\title{
Perfectionism and Writing Performance of Chinese EFL College Learners
}

\author{
Lijing $\operatorname{Lin}^{1}$ \\ ${ }^{1}$ Department of Linguistics, Faculty of English Language and Culture, Guangdong University of Foreign Studies, \\ Guangdong, China \\ Correspondence: Lijing Lin, Department of Linguistics, Faculty of English Language and Culture, Guangdong \\ University of Foreign Studies, Guangdong, Guangzhou, China.
}

Received: May 26, 2020

Accepted: June 25, 2020

Online Published: July 10, 2020

doi: $10.5539 /$ elt.v13n8p35

URL: https://doi.org/10.5539/elt.v13n8p35

\begin{abstract}
In the second language acquisition domain, researchers have devoted tremendous efforts to studying the relationship between L2 learning and some socio-affective factors, such as anxiety, motivation, etc. However, little research has been done to examine whether and how perfectionism, a psychological trait, affects L2 learning and L2 performance. The present study aims to fill this gap and investigate the relationship between the level of perfectionism and L2 performance among Chinese EFL college learners. Two specific questions are raised: (1) What is the relationship between perfectionism and L2 writing performance in terms of linguistic complexity, accuracy, and fluency? (2) What is the relationship between the six dimensions of perfectionism (Concern over Mistakes, Personal Standards, Parental Expectations, Parental Criticism, Doubts about Actions, Organization) and L2 writing performance in terms of linguistic complexity, accuracy, and fluency?

To answer these questions, forty second-year students from Guangdong University of Foreign Studies majoring in English participated in the present study. The participants were required to compose a piece of English argumentative writing on the online system and then complete a 35-item Multidimensional Perfectionism Scale online immediately. The collected data were then processed and analyzed through SPSS (v. 17).

The results of the analysis revealed that: (1) one of the measures of syntactic complexity has a significant negative relationship with perfectionism; (2) Personal Standards, one of the six dimensions of perfectionism, has a significant negative relationship with the participants' L2 writing performance; (3) both Parental Expectations and Parental Criticism are found negatively correlated with the fluency aspect of the writing performance and the relationships have a significant effect. The implications of the findings are suggested for pedagogy and L2 learning.
\end{abstract}

Keywords: Chinese EFL Learners, Correlation, L2 Writing Performance, Perfectionism

\section{Introduction}

\subsection{Research Orientation}

This research intends to find out the relationship between the level of perfectionism and L2 writing performance among Chinese EFL college learners, utilizing a 35-item multidimensional questionnaire - Frost Multidimensional Perfectionism Scale (FMPS) - developed by Frost (1990) and his colleagues. To achieve this end, a question has been raised: does perfectionism affect the writing performance of Chinese EFL students at college level? This research focuses on analyzing what kind of influence Chinese EFL students' perfectionism has on their writing performance and to what extent. The analysis is followed by a discussion of the implication for pedagogy and L2 learning.

\subsection{Rationale and Significance of the Present Study}

Perfectionism used to be a research topic among psychologists and psychiatrists, who strived to build the construct of and investigate the multidimensionality of perfectionism (e.g., Frost et al., 1990; Hewitt \& Flett, 1991). Researchers were also interested in how perfectionistic tendency exerts either positive or negative influences on one's personality style, and thus differentiating normal and neurotic perfectionists (e.g., Hamachek, 1978). Other researchers focused on developing perfectionism scales (e.g., Burns, 1983; Frost et al., 1990; Hewitt \& Flett, 1991; Chan, 2007) and delved into the viability of the scales. 
Later, more and more studies were done in the field of educational psychology, investigating the relationship between perfectionism and academic achievement (see Madigan, 2019). Notably, in these studies, academic achievement was measured in terms of individual test performance (e.g., end of term exams), class performance (e.g., grades) and performance across classes (e.g., grade point average, GPA) (Madigan, 2019), which didn't specify any minor aspect of the student's academic performance, that is, L2 performance.

It is also noticeable that although some socio-affective factors, such as anxiety, motivation, etc. have been extensively studied in the domain of second language acquisition, little research has been done to examine whether perfectionism, a psychological trait, affects L2 learning and L2 performance either positively or negatively. Hence, the present study aims to fill this gap and explore how English as a foreign language (EFL) learners' perfectionism is related to their English writing performance, with a sample of 40 second-year students in GDUFS who are English majors.

\subsection{Research Questions}

To fill the before-mentioned gap, the present study intends to figure out the relationship between Chinese EFL college learners' perfectionism and their English writing performance by adopting a 35-item multidimensional questionnaire - Frost Multidimensional Perfectionism Scale (FMPS) (Frost et al., 1990). Specifically, the present research attempts to answer the following two questions:

1) What is the relationship between perfectionism and L2 writing performance in terms of linguistic complexity, accuracy, and fluency?

2) What is the relationship between the six dimensions of perfectionism (Concern over Mistakes, Personal Standards, Parental Expectations, Parental Criticism, Doubts about Actions, Organization) and L2 writing performance in terms of linguistic complexity, accuracy, and fluency?

\section{Literature Review}

\subsection{Definitions of Perfectionism}

In terms of definition, perfectionism is often linked to setting high personal standards, excessive concern over making mistakes, perception of high parental expectations, worry about high parental criticism, doubt of the quality of one's action and a preference for order and organization (Frost et al., 1990).

Hewitt and Flett (1991) also delved into the multidimensionality of perfectionism and put perfectionism in both self and social contexts, proposing three perfectionism dimensions, namely self-oriented perfectionism, other-oriented perfectionism, and socially prescribed perfectionism. Self-oriented perfectionism is defined as the perfectionistic behavior directed to a person himself, involving "setting exacting standards for oneself and stringently evaluating and censuring one's own behavior" (p. 3). Other-oriented perfectionistic behavior is directed outward, including the setting of unrealistically high standards for others' abilities and performance. Different from self-oriented and other-oriented perfectionism, socially prescribed perfectionism is attributed to others who hold unrealistic beliefs and expectations for and consequently exert pressure on an individual (Hewitt \& Flett, 1991).

Apart from the multidimensionality of perfectionism, researchers were also interested in how perfectionistic tendency exerts either positive or negative influences on one's personality style. Thus, Hamachek (1978) classified perfectionists into normal and neurotic perfectionists. The former tend to set high standards for themselves, yet they "feel free to be less precise as the situation permits" (p. 27). Neurotic perfectionists also set high standards but are less tolerant of making mistakes, which renders them always dissatisfied with their achievements (Hamachek, 1978).

Perfectionism is often associated with other psychological traits and psychopathology symptoms. Gregersen and Horwitz (2002) conducted research among language learners with different degrees of anxiety and looked into their reactions to their oral performance and found that perfectionism is linked to anxiety. They thus suggested that procedures used to overcome perfectionism be adopted to mitigate foreign language learners' anxiety. It has also been tested that perfectionism is associated with a variety of psychopathology symptoms, compulsive experiences, and procrastination (Frost et al., 1990).

In this study, the definition of perfectionism proposed by Frost et al. (1990) was adopted. The reason for this choice of the definition was based on the following consideration. Frost (1990) and his colleagues define perfectionism in terms of a number of dimensions: setting high personal standards, excessive concern over making mistakes, perception of high parental expectations, worry about high parental criticism, doubt of the quality of one's action and a preference for order and organization. So this definition manifests the 
multidimensionality of perfectionism and matches the multiple dimensions specified in the Frost Multidimensional Perfectionism Scale (FMPS) utilized in the study to measure participants' perfectionistic tendencies.

\subsection{The Development of Perfectionism Scales}

Researchers also devoted much effort to develop perfectionism scales. Burns (1983) developed a scale with a deficiency caused by "unidimensional focus on personal standards and concern over mistakes" (Chan, 2007: 79). Later a 35-item multidimensional questionnaire - Frost Multidimensional Perfectionism Scale (FMPS) - by Frost (1990) and his colleague emerged, digging deep into the multiple dimensions of perfectionism. These dimensions include excessive concern over mistakes, high personal standards, the perception of high parental expectations, the perception of high parental criticism, the doubting of the quality of one's actions, and a preference for order and organization (Frost et al., 1990). Hewitt and Flett (1991) also developed a 45-item Multidimensional Perfectionism Scale (MPS) that assesses self-oriented, other-oriented, and socially prescribed perfectionism. Out of the concern that the existing perfectionism scales put too much stress on the negative forms of perfectionism, ignoring that there are also good sides in perfectionism, Chan (2007) designed a Positive and Negative Perfectionism Scale (PNPS), which looks into both positive and negative perfectionism, containing self-oriented perfectionistic items as well as other-oriented ones. All these attempts to develop a perfectionism scale that is comprehensive, reliable, and objective pave the way for future research on the issue of perfectionism and its relation with other domains such as L2 learning.

The perfectionism scale used in this study is the Frost Multidimensional Perfectionism Scale (FMPS), designed by Frost et al. (1990). FMPS is a 5-point Likert scale containing 35 items in total that assess six dimensions of perfectionism - Concern over Mistakes (CM), Personal Standards (PS), Parental Expectations (PE), Parental Criticism (PC), Doubts about Actions (DA), Organization (O).

The reason why the FMPS is adopted in the present study is that it contains several dimensions, ranging from self-oriented perfectionism (CM, PS, DA, O) to socially-prescribed ones (PE, PC), that allow detailed analysis of the causes of perfectionism and provision of specific suggestions to combat any negative perfectionism in accordance.

Burns' perfectionism scale is excluded because of its biased focus on self-oriented perfectionism - personal standards and concern over mistakes (Burns, 1983). The Multidimensional Perfectionism Scale (MPS) designed by Hewitt and Flett (1991) is not suitable for this study either because the L2 writing task in the present study is not collaborative and thus is not likely to provoke interpersonal perfectionistic behavior that is specified in the MPS. The Positive and Negative Perfectionism Scale (PNPS) developed by Chan (2007) is tailored only to gifted children. Although the PNPS contains both self-oriented perfectionistic items and other-oriented ones, the positive and negative dimensions tend to lead participants into approving positive items and disagreeing with negative ones. Besides, the number of items in PNPS (20 items in total) is relatively small, so that it might leave out some perfectionistic behavior.

\subsection{Previous Empirical Studies on Perfectionism}

Previous researchers have delved into the definition of perfectionism and strived to design a multidimensional measure of perfectionism. For instance, Frost et al. (1990) proposed a multidimensional perfectionism scale and tested the nature of perfectionism in four separate studies. They identified six dimensions of perfectionism, namely setting high personal standards, excessive concern over making mistakes, perception of high parental expectations, worry about high parental criticism, doubt of the quality of one's action, and a preference for order and organization (Frost et al., 1990). In their studies, the association between perfectionism and a number of psychopathological symptoms such as compulsive experiences, depression, etc., was also investigated (Frost et al., 1990). Hewitt and Flett (1991) also made a similar attempt to probe into the multidimensional construct of perfectionism and designed another multidimensional perfectionism scale to assess three dimensions of perfectionism they proposed: self-oriented perfectionism, other-oriented perfectionism, and socially-prescribed perfectionism. Their research also suggested the correlation between perfectionism and psychological maladjustment (Hewitt \& Flett, 1991).

Later, the relationship between perfectionism and academic achievement has captured the interest of many educational psychologists. Madigan (2019) conducted an in-depth meta-analysis to explore and generalize their relationship, based on the findings of 37 previous studies. The analysis differentiated two higher-order dimensions of perfectionism - perfectionistic strivings and perfectionistic concerns; the former dimension includes the personal standards subscale, the self-oriented perfectionism subscale, the striving for perfection subscale, the high standards subscale and the striving for excellence subscale while the latter dimension consists 
of the concerns over mistakes, doubts about action, socially prescribed perfectionism, negative reactions to imperfection and discrepancy subscales (Madigan, 2019). Academic achievement was measured in terms of GPA, grade, and examination performance. The results revealed that perfectionistic strivings were significantly and positively correlated to academic performance. In contrast, perfectionistic concerns demonstrated a significant negative relationship with academic achievement (Madigan, 2019).

With more and more research being done to examine the relationship between perfectionism and academic performance, a few researchers started to investigate whether and how perfectionism is correlated with a minor aspect of academic achievement - L2 performance. Rastegar et al. (2017), for example, conducted a study to "explore any significant relationships between perfectionism and its dimensions as a whole and language proficiency of students of Kerman institutes" (p. 1), using the Frost Multidimensional Perfectionism Scale (FMPS). The students in their study were EFL students at intermediate, upper-intermediate, and advanced levels. The result showed that perfectionism and its dimensions as a whole had a significant positive relationship with language proficiency. On the contrary, upon assessing the perfectionism level of, and obtaining grades of four separate skills (reading, speaking, listening, writing) of a sample of 300 junior and senior students of English in Iran, Pishghadam and Akhondpoor (2011) yielded a contrasting result indicating a significant negative relationship between reading, speaking, listening skill, and perfectionism. The perfectionism scale adopted in this study was Ahwaz Perfectionism scale (2000), but not the common perfectionism scales utilized in other research.

As can be seen from the studies mentioned above, the number of research on the relationship between perfectionism and L2 performance is far from enough to give a clear and full picture. In both studies done by Rastegar et al. (2017) and Pishghadam and Akhondpoor (2011), researchers took a holistic conceptualization of perfectionism, which failed to manifest the multidimensionality of perfectionism. The two studies examined participants' L2 performance, however, in completely different ways. Rastegar et al. (2017) elicited the participants' scores of the Michigan Test of English Language Proficiency (Briggs et al., 1997), which was a holistic assessment of participants' L2 performance. Although Pishghadam and Akhondpoor (2011) obtained participants' grades of four separate skills (reading, speaking, listening, writing) to have a comprehensive picture of participants' L2 performance, the skill of writing was shown not to have any significant relationship with perfectionism.

Therefore, the present study is designed to fill these gaps and strives to draw a clearer picture of the relationship between L2 writing performance and perfectionism, manifesting the multidimensionality of perfectionism and three linguistic aspects of L2 writing.

\section{Research Methods}

\subsection{Participants}

Forty second-year students from Guangdong University of Foreign Studies who major in English participated in the present study, including 8 males and 32 females. These Chinese students had learned English as a foreign language at schools for at least 8 years, and they were selected from two natural classes of grade two in the Faculty of English Language and Culture.

\subsection{Instruments}

Two instruments were utilized in the present study to measure variables: an argumentative writing task and the Frost Multidimensional Perfectionism Scale (FMPS) (Frost et al., 1990).

\subsubsection{Argumentative Writing Task}

An argumentative writing task was designed on the topic of Internet buzzwords. The materials were provided and evaluated by professional English writing teachers to ensure that the difficulty of the task was suitable for the subjects. The writing task required participants first to summarize the pro and con sides' opinions on the use of Internet buzzwords according to the materials and then give their own opinions on this issue.

\subsubsection{Frost Multidimensional Perfectionism Scale (FMPS)}

The Frost Multidimensional Perfectionism Scale (FMPS), designed by Frost et al. (1990), was utilized to measure the perfectionistic tendency of the participants. MPS is a 5-point Likert scale with five alternatives: 1 (Strongly Disagree), 2 (Disagree), 3 (Not Sure), 4 (Agree), and 5 (Strongly Agree). It consists of six subscales and altogether 35 items that assess different dimensions of perfectionism - Concern over Mistakes (CM), Personal Standards (PS), Parental Expectations (PE), Parental Criticism (PC), Doubts about Actions (DA), Organization (O). A total score, which indicates perfectionism, can be obtained by adding the 35 items together. 
Higher scores manifest a higher level of perfectionism, whereas lower scores display smaller perfectionistic tendencies. The reliability of the FMPS has been computed, and it showed that the subscales' coefficients of internal consistency ranged from .77 to .93 and that the reliability of the total scale was .90 (Frost et al., 1990).

\subsection{Data Collection}

The study was carried out online. To relieve the participants' burden, they were told by their writing teacher that it was an exercise and would not be counted as part of their final scores of the course.

Before the participants did the experimental task, the writing teacher read the instruction and explained the procedure to them during the writing class, making sure that they understood how to finish the task online. The participants were then required to compose a piece of English argumentative writing after class on the online system www.pigai.org. The instruction and materials were all presented on this platform. Participants had to finish the composition within 60 minutes and write about 300 words. The topic of the writing was identical for each participant to ensure that the difficulty of the task was even. All the writings were collected and assessed automatically by the online system. The use of this online system provides a fair and reliable assessment of all the participants' writings. To prevent participants from being aware of the purpose of the research prior to the writing task, they were required to finish the Frost Multidimensional Perfectionism Scale (FMPS) right after finishing their writing, on a questionnaire distribution website - https://www.wjx.cn/. The FMPS needs 10 to 15 minutes to complete. So the whole procedure lasted for 70 to 75 minutes.

\subsection{Data Coding and Analysis}

\subsubsection{Data Coding}

There were 40 students who both finish the writing task and the scale. The linguistic errors in each text were marked and calculated by the researcher.

\subsubsection{Writing Production Measures}

The scores of the writing samples were given by www.pigai.org. The computer algorithm of this online system evaluates English writing by comparing the uploaded writing with a standard corpus in terms of vocabulary, grammar, structure, and pertinence with the topic.

In the field of second language acquisition, the notions of complexity, accuracy, and fluency are often used to evaluate L2 learners' L2 performance and L2 proficiency (Skehan, 1998; Ellis, 2003, 2008; Ellis \& Barkhuizen, 2005). Based on several researchers' findings, some widely used measures were adopted to evaluate the accuracy, fluency, lexical complexity and syntactic complexity of Chinese EFL learners' writing production.

In the present study, accuracy was measured by error-free T-units per T-units (EFT/T), which is defined by the proportion of T-units that are free of errors (Arent, 2003; Rahimpour, 2010). According to Wolfe-Quintero, Inagaki and Kim's (1998) findings, the ratio of error-free T-units is an appropriate measure for proficient L2 learners and was thus adopted to measure the accuracy of participants' writing production in the present study, as the participants were upper-intermediate EFL learners majoring in English. In Hunt's (1965) definition, T-unit is "one main clause plus whatever subordinate clauses happen to be attached to or embedded within it" (p. 4). As a result, a simple or complex sentence is seen as one T-unit, whereas a compound or compound-complex constitutes several T-units. In terms of errors, typical errors made by Chinese EFL learners summarized by Wang and Wang (2015) including number agreement, incorrect use of articles, misuse of the copula, misuse of non-finite verbs, and tense errors, plus syntactic errors and inappropriate lexical choice were counted as errors in the present study. Spelling mistakes such as capitalization and punctuation, however, were not regarded as errors.

The mean number of words per T-unit (W/T), which means the total number of words of the text divided by the total number of T-units (Ishikawa, 2007), was adopted to measure the fluency of the participants' writing samples. The larger the number, means greater fluency.

In terms of the complexity of the writing, both syntactic complexity and lexical complexity were taken into consideration. The measurement of both syntactic and lexical complexity was done by the web-based version of Lexical Complexity Analyzer and L2 Syntactic Complexity Analyzer developed by Lu (2010, 2011). They are reliable tools that allow language teachers and researchers to analyze the lexical and syntactic complexity of written English production, utilizing a number of measures proposed in the first and second language development literature.

Two measures were adopted to reveal lexical complexity: lexical sophistication, and mean segmental type/toke (MSTTR). Linnarud (1986) and Hyltenstam (1988) defined lexical sophistication as the ratio of the number of 
sophisticated lexical words to the total number of lexical words in a text. MSTTR, another lexical variation measure, refers to the range of vocabulary a learner used in his or her production ( $\mathrm{Lu}, 2012)$.

The syntactic complexity was measured by mean length of sentence (MLS), clause per T-units (C/T), and coordinate phrase per clause $(\mathrm{CP} / \mathrm{C})$. MLS is calculated by the total number of words in a text to the number of sentences. $\mathrm{C} / \mathrm{T}$, reflecting the amount of subordination, refers to the ratio of the total number of clauses to the total number of $\mathrm{T}$-units in the text. $\mathrm{CP} / \mathrm{C}$ means the ratio of the total number of coordinate phrases to the total number of clauses (Rahimpour \& Hosseini, 2010; Ishikawa, 2007; Gilabert, 2007; Robinson, 1995).

Table 1 summarizes all the measures used in the present study to assess participants' writing performance in aspects of accuracy, fluency, lexical and syntactic complexity.

Table 1. Measures for accuracy, fluency, and complexity

\begin{tabular}{cc}
\hline Variables & Measures \\
\hline Accuracy & error-free T-units per T-units \\
Fluency & mean number of words per T-unit \\
Lexical complexity & lexical sophistication \\
& mean segmental type/toke ratio \\
Syntactic complexity & mean length of sentence \\
& clause per T-units \\
& coordinate phrase per clause \\
\hline
\end{tabular}

\subsubsection{Data Analysis}

The digital data were submitted to the Lexical Complexity Analyzer and L2 Syntactic Complexity Analyzer on http://aihaiyang.com/software/ to obtain the results of the 5 before-mentioned complexity measures, as well as the number of words and T-unit. With the number of error-free T-units calculated by the researcher, the data of accuracy and fluency measures were counted by Microsoft Excel.

The researcher then used SPSS (V. 17) to analyze and interpret all the well-grouped data. To find out the relationship between perfectionism and the writing performance of Chinese EFL students at college level, correlation analysis was employed in the present study.

\section{Results and Discussion}

\subsection{Overall Results for the Writing Performance and the Questionnaire}

As shown in Table 2 and Table 3, there were 40 participants in the study. The descriptive statistics of the writing performance and the questionnaire are presented below.

Table 2. The means and standard deviation of the writing performance

\begin{tabular}{cccc}
\hline & $\mathrm{N}$ & Mean & SD \\
\hline Writing score & 40 & 81.7125 & \\
Accuracy & & & .26739 \\
EFT/T & 40 & .3115 & \\
Fluency & & & 3.06665 \\
W/T & 40 & 17.0322 & \\
Lexical Complexity & & & .05544 \\
LS & 40 & .2707 & .03655 \\
MSTTR & 40 & .7598 & 3.99822 \\
Syntactic Complexity & & & .22814 \\
MLS & 40 & 18.7129 & .14640 \\
C/T & 40 & 1.6594 & .3669 \\
CP/C & 40 & $T$
\end{tabular}

Note. $\mathrm{EFT} / \mathrm{T}=$ error-free T-units per T-units; $\mathrm{W} / \mathrm{T}=$ words per T-unit; $\mathrm{LS}=$ lexical sophistication; MSTTR $=$ mean segmental type/toke ratio; MLS $=$ mean length of sentence; $\mathrm{C} / \mathrm{T}=$ clause per $\mathrm{T}$-unit; $\mathrm{CP} / \mathrm{C}=$ coordinate phrase per clause. 
Table 3. The means and standard deviation of the questionnaire

\begin{tabular}{cccc}
\hline & N & Mean & SD \\
\hline Perfectionism & 40 & 74.9250 & 12.020004 \\
CM & 40 & 21.8500 & 5.95087 \\
PS & 40 & 20.6500 & 4.23992 \\
PE & 40 & 12.7750 & 3.21445 \\
PC & 40 & 8.2250 & 2.74084 \\
D & 40 & 11.4250 & 2.87239 \\
O & 40 & 22.1750 & 3.54377
\end{tabular}

Note. $\mathrm{CM}=$ Concern over Mistakes; PS $=$ Personal Standards; PE = Parental Expectations; $\mathrm{PC}=$ Parental Criticism; $\mathrm{D}=$ Doubts about Actions; $\mathrm{O}=$ Organization.

\subsection{Results for Research Questions 1}

The first question of the present study is: What is the relationship between perfectionism and L2 writing performance in terms of linguistic complexity, accuracy, and fluency? To investigate their relationships, Pearson Correlation was conducted.

Table 4. Results of Pearson Correlation analysis between perfectionism and L2 writing performance

\begin{tabular}{cc}
\hline & perfectionism \\
\hline L2 writing performance & -.204 \\
Writing score & \\
Accuracy & .012 \\
EFT/T & \\
Fluency & -.181 \\
W/T & \\
Lexical complexity & -.027 \\
LS & -.024 \\
MSTTR & \\
Syntactic complexity & -.126 \\
MLS & .073 \\
C/T & $-.313^{*}$ \\
CP/C &
\end{tabular}

Note. $\mathrm{EFT} / \mathrm{T}=$ error-free T-units per T-units; $\mathrm{W} / \mathrm{T}=$ words per T-unit; $\mathrm{LS}=$ lexical sophistication; MSTTR $=$ mean segmental type/toke ratio; MLS = mean length of sentence; $\mathrm{C} / \mathrm{T}=$ clause per $\mathrm{T}$-unit; $\mathrm{CP} / \mathrm{C}=$ coordinate phrase per clause.

${ }^{*} \mathrm{P}<.05$.

As indicated in Table 4, the correlation between perfectionism and L2 writing performance, $r=-.204$, is negative but not significant. The relationship between perfectionism and accuracy is positive, while the relationship between perfectionism and fluency is negative; both relationships are not significant. As for the complexity aspect of the writing, both measures of lexical complexity are negatively correlated with perfectionism, without significant effect. Among three measures of syntactic complexity, only the relationship between coordinate phrase per clause $(\mathrm{CP} / \mathrm{C})$ and perfectionism has significance $(\mathrm{r}=-.313)$. Except for clause per $\mathrm{T}$-unit $(\mathrm{C} / \mathrm{T})$ that has a positive relationship with perfectionism, the mean length of sentence (MLS) and coordinate phrase per clause $(\mathrm{CP} / \mathrm{C})$ are both negatively correlated with perfectionism.

\subsection{Results for Research Questions 2}

The second question of the present study is: What is the relationship between the six dimensions of perfectionism (Concern over Mistakes, Personal Standards, Parental Expectations, Parental Criticism, Doubts about Actions, Organization) and L2 writing performance in terms of linguistic complexity, accuracy, and 
fluency? To answer this question, correlation coefficients were computed between the variables mentioned above.

Table 5. Results of Person Correlation analysis between six dimensions of perfectionism and L2 writing performance

\begin{tabular}{ccccccc}
\hline & CM & PS & PE & PC & D & O \\
\hline $\begin{array}{c}\text { L2 writing performance } \\
\text { Writing score }\end{array}$ & -.229 & $-.323^{*}$ & .015 & .125 & -.089 & -.028 \\
$\begin{array}{c}\text { Accuracy } \\
\text { EFT/T }\end{array}$ & -.015 & -.070 & .245 & .116 & -.164 & -.024 \\
Fluency & & & & & & \\
W/T & -.123 & .092 & $-.337^{*}$ & $-.340^{*}$ & -.041 & .025 \\
Lexical complexity & & & & & & \\
LS & .031 & -.030 & -.022 & -.146 & -.007 & .023 \\
MSTTR & .006 & .056 & -.203 & -.025 & -.058 & .085 \\
Syntactic complexity & & & & & & \\
MLS & -.036 & .023 & -.277 & -.277 & .060 & -.019 \\
C/T & .144 & .182 & -.170 & -.182 & .117 & .014 \\
CP/C & -.159 & -.225 & -.213 & -.261 & -.195 & -.079
\end{tabular}

Note. $\mathrm{EFT} / \mathrm{T}=$ error-free T-units per T-units; $\mathrm{W} / \mathrm{T}=$ words per T-unit; LS $=$ lexical sophistication; MSTTR $=$ mean segmental type/toke ratio; MLS = mean length of sentence; $\mathrm{C} / \mathrm{T}=$ clause per $\mathrm{T}$-unit; $\mathrm{CP} / \mathrm{C}=$ coordinate phrase per clause; $\mathrm{CM}=$ Concern over Mistakes; $\mathrm{PS}=$ Personal Standards; $\mathrm{PE}=$ Parental Expectations; $\mathrm{PC}=$ Parental Criticism; $\mathrm{D}=$ Doubts about Actions; $\mathrm{O}=$ Organization.

${ }^{*} \mathrm{P}<.05$.

As can be seen from Table 5, the correlations between six dimensions of perfectionism and L2 writing performance and its three aspects are complex. Only Personal Standards (PS) has a significant and negative correlation ( $\mathrm{r}=-.323)$ with L2 writing performance. Except for PS, among all dimensions of perfectionism, Concern over Mistakes (CM), Doubts about Actions (D), and Organization (O) are negatively correlated with L2 writing performance but don't have any significant effect. Notably, both Parental Expectations (PE) and Parental Criticism (PC) have negative relationships with fluency, and their correlations have a significant effect $(\mathrm{r}=-.337$ and $\mathrm{r}=-.340$, respectively). It is also noticeable that coordinate phrase per clause $(\mathrm{CP} / \mathrm{C})$, one of the measures of syntactic complexity, is negatively correlated with all six dimensions of perfectionism, but all the relationships are not significant.

\subsection{Discussion}

The findings of the present study aim to answer the two research questions which sought to find out the relationship between perfectionism and the writing performance of Chinese EFL students at college level.

Perfectionism has a negative though not significant relationship with the participants' L2 writing performance. However, the findings reveal that Coordinate phrase per clause $(\mathrm{CP} / \mathrm{C})$ is negatively correlated with perfectionism, and their relationship has a significant effect. This could indicate that a higher perfectionism level may lead to less frequent production of coordinate phrases. This is probably due to perfectionistic L2 learners' worry that they might make mistakes when trying to increase their syntactic complexity in their writing by producing coordinate phrases.

Among all dimensions of perfectionism, Personal Standards (PS) has a significant and negative relationship with the participants' L2 writing performance. This finding suggests that high personal standards may impair L2 writing performance. It has also been found that Parental Expectations (PE) and Parental Criticism (PC) are negatively correlated with fluency, and the relationships have a significant effect. It is noteworthy that both PE and PC can be grouped into socially-prescribed perfectionism, which indicates that socially-prescribed perfectionism may result in lower fluency. This is probably because of the pressure and fear of failing to meet the 
social standards and getting punishment.

\section{Conclusion and Implication}

\subsection{Summary of Major Findings}

The present study aims to investigate the relationship between perfectionism and the writing performance of Chinese EFL students at college level. According to the results reported in Chapter 4, the major findings can be summarized as follows:

Firstly, one of the measures of syntactic complexity-coordinate phrase per clause $(\mathrm{CP} / \mathrm{C})$ has a negative and significant relationship with perfectionism, which indicates that a higher level of perfectionism may impede L2 learners from generating coordinate phrases.

Secondly, Personal Standards (PS), one of the six dimensions of perfectionism, has a significant and negative relationship with the participants' overall L2 writing performance. This finding suggests that perfectionistic L2 learners' higher personal standards may lead to worse L2 writing performance.

Thirdly, both Parental Expectations (PE) and Parental Criticism (PC) are found to be negatively correlated with fluency, and the relationships have a significant effect. Both PE and PC, perfectionism dimensions that are induced by society, can be deemed as socially-prescribed perfectionism, indicating that socially-prescribed perfectionism may cause lower fluency in L2 learner's writing production.

\subsection{Implications}

According to the present study's findings, perfectionism tends to negatively affect the writing performance of Chinese EFL students at college level. Thus, it is necessary to provide suggestions to combat problems associated with forms of perfectionism that impair L2 learners' writing performance.

As for L2 learners, they should accept that "errors are normal, expected, and often necessary aspects of the learning process" (Brophy \& Jere, 1996: 3) and they ought to set realistic and moderate expectations for themselves.

Brophy and Rohrkemper (1989) suggested a list of methods for teachers to help and support perfectionistic students:

[1] building a friendly, supportive learning environment;

[2] establishing the expectation that mistakes are a normal part of the learning process;

[3] presenting themselves as helpful instructors concerned primarily with promoting student learning, rather than as authority figures concerned primarily with evaluating student performance;

[4] articulating expectations that stress learning and improvement over perfect performance of assignments;

[5] explaining how perfectionism is counterproductive;

[6] reassuring perfectionist students that they will get the help they need to achieve success;

[7] following through with help, and communicating teacher approval of students' progress and accomplishments.

The present research also finds that socially-prescribed perfectionism (Parental Expectations and Parental Criticism) affects the fluency in L2 learners' writing production. Hence, parents should not set unrealistic goals for their children or even punish them when they fail to conform to unreasonable standards.

\subsection{Limitations}

Some limitations of this study must be noted. First, the number of subjects in this study is small, and thus the generalizability of the findings might be limited. Second, since the topic of this study is quite new, relevant literature is limited. Thus the findings of the present study cannot be compared with other studies. More studies are needed in this field in the future.

\section{References}

Ai, Haiyang \& Lu, Xiaofei. (2010). A web-based system for automatic measurement of lexical complexity. Paper presented at the 27th Annual Symposium of the Computer-Assisted Language Consortium (CALICO-10). Amherst, MA. June 8-12.

Ai, Haiyang \& Lu, Xiaofei. (2013). A corpus-based comparison of syntactic complexity in NNS and NS university students' writing. In Ana Díaz-Negrillo, Nicolas Ballier, and Paul Thompson (eds.), Automatic Treatment and Analysis of Learner Corpus Data, 249-264. Amsterdam/Philadelphia: John Benjamins. 
https://doi.org/10.1075/scl.59.15ai

Arent, R. (2003). Promoting revision and development in L2 writing through a combination-based curriculum. The Korea TESOL Journal, 6(1), 1-26.

Briggs, S., Dobson, B., Rohlick, Th., Spann, M., \& Strom, E. (1997). Examination for the Certificate of Proficiency in English, 4-7.

Brophy, \& Jere. (1996). Working with perfectionist students. eric digest. Academic Aspiration(October), 3.

Brophy, J., \& M. Rohrkemper. (1989). TEACHERS' STRATEGIES FOR COPING WITH PERFECTIONIST STUDENTS. Research Series No. 198. East Lansing, MI: Institute for Research on Teaching, Michigan State University. ED 314401.

Burns, D. D. (1983). The spouse who is a perfectionist. Medical Aspects of Human Sexuality, 17, 219-230.

Chan, David W. (2007). Positive and negative perfectionism among Chinese gifted students in Hong Kong: their relationships to general self-efficacy and subjective well-being. Journal for the Education of the Gifted, 31(2), 77-102. https://doi.org/10.4219/jeg-2007-512

Ellis, R. \& G. Barkhuizen. (2005). Analysing Learner Language. Oxford University Press.

Ellis, R. (2003). Task-based Language Learning and Teaching. Oxford University Press.

Ellis, R. (2008). The Study of Second Language Acquisition. 2nd edn. Oxford University Press.

Frost, R. O., Marten, P., Lahart, C., \& Rosenblate, R. (1990). The dimensions of perfectionism. Cognitive Therapy and Research, 14(5), 449-468. https://doi.org/10.1007/BF01172967

Gilabert, R. (2007). The simultaneous manipulation of task complexity along planning time and [+/-Here-and-Now]: Effects on L2 oral production. Investigating tasks in formal language learning, 44-68. https://doi.org/10.21832/9781853599286

Gregersen, T., \& Horwitz, E. K.. (2002). Language learning and perfectionism: anxious and non-anxious language learners' reactions to their own oral performance. Modern Language Journal, 86(4), 562-570. https://doi.org/10.1111/1540-4781.00161

Hamachek, D. E. (1978). Psychodynamics of normal and neurotic perfectionism. Psychology: A Journal of Human Behavior, 15(1), 27-33.

Hewitt, P. L., \& Flett, G. L. (1991). Perfectionism in the self and social contexts: conceptualization, assessment, and association with psychopathology. Journal of Personality \& Social Psychology, 60(3), 456-470. https://doi.org/10.1037//0022-3514.60.3.456

Hunt, W. (1965). Grammatical Structures Written at Three Grade Levels. Urbana, IL: The National Council Teachers of English.

Hyltenstam, K. (1988). Lexical characteristics of near-native second-language learners of Swedish. Journal of Multilingual and Multicultural Development, 9, 67-84. https://doi.org/10.1080/01434632.1988.9994320

Ishikawa, T. (2007). The effect of manipulating task complexity along the [+/-Here-and-Now] dimension on L2 written narrative discourse. Investigating tasks in formal language learning, 136-156. https://doi.org/10.21832/9781853599286-010

Linnarud, M. (1986). Lexis in composition: A performance analysis of Swedish learners' -written English. Lund, Sweden: CWK Gleeru.

Lu, Xiaofei \& Ai, Haiyang. (2015). Syntactic complexity in college-level English writing: Differences among writers with diverse L1 backgrounds. Journal of Second Language Writing, 29, 16-27. https://doi.org/10.1016/j.jslw.2015.06.003

$\mathrm{Lu}$, Xiaofei. (2010). Automatic analysis of syntactic complexity in second language writing. International Journal of Corpus Linguistics, 15(4), 474-496. https://doi.org/10.1075/ijcl.15.4.02lu

$\mathrm{Lu}$, Xiaofei. (2011). A corpus-based evaluation of syntactic complexity measures as indices of college-level ESL writers' language development. TESOL Quarterly, 45(1), 36-62. https://doi.org/10.5054/tq.2011.240859

$\mathrm{Lu}$, Xiaofei. (2012). The Relationship of Lexical Richness to the Quality of ESL Learners' Oral Narratives. The Modern Language Journal, 96(2), 190-208. https://doi.org/10.1111/j.1540-4781.2011.01232_1.x

Madigan, D. J. (2019). A meta-analysis of perfectionism and academic achievement. Educational Psychology Review, 31, 967-989. https://doi.org/10.1007/s10648-019-09484-2 
Pacht, A. (1984). Reflections on perfection. American Psychologist, 39(4), 386-390. https://doi.org/10.1037/0003-066X.39.4.386

Pishghadam, R., \& Akhondpoor, F. (2011). Learner Perfectionism and Its Role in Foreign Language Learning Success, Academic Achievement, and Learner Anxiety. Journal of Language Teaching and Research, 2, 432-440. https://doi.org/10.4304/j1tr.2.2.432-440

Rahimpour, M., \& Hosseini, P. (2010). The impact of task complexity on L2 learners' written narratives. English Language Teaching, 3(3), 198. http://dx.doi.org/10.5539/elt.v3n3p198

Robinson, P. (1995a). Task complexity and second language narrative discourse. Language Learning 45, 99-140. https://doi.org/10.1111/j.1467-1770.1995.tb00964.x

Skehan, P. (1998). A Cognitive Approach to Language Learning. Oxford University Press. https://doi.org/10.1177/003368829802900209

Wang, Chuming \& Wang, Min. (2015). Effect of alignment on 12 written production. Applied Linguistics, 36(5), 503-526. https://doi.org/10.1093/applin/amt051

Wolfe-quintero, K., Inagaki, S. \& Kim, H. (1998). Second language development in writing: measures of fluency, accuracy and complexity. Second Language Teaching \& Curriculum Center, University of Hawaii.

\section{Copyrights}

Copyright for this article is retained by the author(s), with first publication rights granted to the journal.

This is an open-access article distributed under the terms and conditions of the Creative Commons Attribution license (http://creativecommons.org/licenses/by/4.0/). 